expansion of technical education. Perhaps the Advisory Council on Scientific Policy, which although closely concerned with the matter is not directly involved, would put the weight of its authority behind such an inquiry; it should at least be able to command the support of the British Institute of Management and of leading industrialists, as was indicated in the discussion which followed Sir Ewart Smith's paper at the Birmingham meeting of the British Association.

\section{DECLASSIFIED WORK ON UNDER-WATER EXPLOSIONS}

Underwater Explosions

By Robert H. Cole. Pp. ix +437. (Princeton, N.J. : Princeton University Press; London: Oxford University Press, 1948.) 42s. net.

A FEW weeks before the Battle of Britain, Sir Geoffrey Taylor suggested that I should attempt to calculate the pressure pulse caused by the detonation of an explosive charge of TNT in water, beginning with Prof. H. Jones's numerical values of the adiabatic of the detonation products. The calculations were the most tedious I have ever made. However, after four months I had a curve showing the form of the pulse at 50 charge-radii. For the first time I was allowed to see the experimental results, a tracing made by Sir Geoffrey from a specially secret Admiralty report, produced by Sir Geoffrey after certain formalities had been observed. The agreement between theory and experiment was encouraging. Taturally, I wanted more data, and soon I was allowed to study Hilliar's report.

Seldom does a secret scientific document compare in skill, insight and language with the outstanding scientific papers of any decade; but Hilliar's report, written in 1919, merits such comparison. Mechanical ingenuity, a sound grasp of theoretical principles, and a wide and accurate range of experimental data in a hitherto almost unknown field are all there. The formal, terse and impeccable language in which this humble scientific worker presented his results to the Lords of the Admiralty is delightful. Sir Ernest Gowers could do no better.

The ban of secrecy on this and many other reports on the same subject has now been removed, and R. H. Cole's "Underwater Explosions" gives a very fine account of the present position. The book summarizes the main results of well over a hundred reports, many of them not yet published openly. Free use is made of appropriate openly published papers and text-books. The most recent papers naturally receive greater attention than the early ones ; but some of the early papers were outstanding at the time when they were written.

The subject as left by Hilliar was physics; the subject as it now stands revealed by Cole is technology. The ubiquitous cathode ray tube and the efforts of many skilful and industrious mathematicians have extended the state of knowledge shown in Hilliar's report, but only a few striking new ideas have been added.

The book is divided into ten chapters, an appendix, a bibliography and an index. The chapter headings are: the sequence of events in an underwater explosion, hydrodynamical relations, the detonation process in explosives, theory of the shock wave, measurement of underwater explosion pressures, photography of underwater explosions, shock-wave measurements, motion of the gas sphere, secondary pressure waves, and surface and other effects. The appendix develops some of the approximations special to water in the Kirkwood-Bethe theory of the spherical propagation of an explosion pulse.

Possibly the most interesting sections of the book are those giving the theory and the experiment of pulsating underwater bubbles, especially when modified by free and rigid surfaces. Apparently the essentials of this problem were first formulated by an unknown examiner in a Cambridge Tripos exam. ination in the eighteen-fifties. Butterworth, in the Admiralty, during the interval between the two World Wars, rediscovered the problem and worked out many interesting features of underwater explosions. During the Second World War, Taylor, Herring and others made considerable extensions. An omission which is slightly disappointing is that the chapter on surface effects does not mention gravity waves caused by underwater explosions. In a purely scientific sense, the gravity waves caused by explosions are most interesting and give substance to the brilliant theories of Cauchy and Poisson.

There are very few misprints in the book, but Dr. A. B. Wood's name is mis-spelt as Ward in several places, both in the text and in the bibliography.

As I have stated, many of the papers on which Cole's book is based have not yet been published. This unfortunate situation is being corrected by the joint efforts of the United States Navy Department and the Admiralty. A compendium in three volumes on underwater explosions, containing many of the reports written during 1914-48 in Americe and the United Kingdom, is being prepared for open publication. No known scientific fact in the fundementel physics of underwater explosions is being withheld. This compendium, together with Cole's book, will give a comprehensive account of the subject as it stands to-day.

Cole's book is highly recommended for all physics and mathematics libraries on the grounds that it is well written, substantial and novel. Students and research workers not concerned with the subject will find much to interest them. The photographs are entertaining and illustrate the theory in striking fashion.

W. G. PENNey

\section{ARCHAOLOGY AND SCIENCE}

A Hundred Years of Archæology

By Dr. Glyn E. Daniel. (The Hundred Years Series.) Pp. 344. (London: Gerald Duckworth and Co., Ltd., 1950.) 21s. net.

ACHACOLOGY is, in many respects, a subject which links the humanities with science. Its chief aim is to deseribe the early history of man on the basis of the relies of his handiwork (with the exclusion of written records); in other words, to supplement history, to extend it back to the beginnings of mankind and to develop a sort of prehistoric social anthropology. But in addition, archæology seeks to trace the evolution of human technology and to reconstruct the ecology of prehistoric and early historic man. In these respects it is intimately connected with geology, palæontology, physical anthropology and comparative anatomy. As in the 